\title{
Relationship between bone mineral density and the frequent administration of epidural steroid injections in postmenopausal women with low back pain
}

\author{
Sungyun Kim MD, Byeongmun Hwang MD PhD
}

S Kim, B Hwang. Relationship between bone mineral density and the frequent administration of epidural steroid injections in postmenopausal women with low back pain. Pain Res Manag 2014;19(1):30-34.

BACKGROUND: Epidural steroid injection (ESI) is one of the most common nonsurgical treatments for low back pain. In general, corticosteroid therapy often results in bone loss and osteoporosis. In previous studies, bone mineral density (BMD) was evaluated after epidural injections of relatively small numbers and relatively low total doses of corticosteroids. However, the relationship between BMD and multiple ESIs remains to be elucidated.

OBJECTIVE: To explore the relationship between BMD and multiple ESIs in postmenopausal women with low back pain.

METHODS: Medical records of postmenopausal women with low back pain treated with or without ESIs were reviewed. BMD was measured in the lumbar spine, femoral neck and total femur after the treatments. A total of 71 patients were divided into two groups: group 1 included patients who had received non-ESI medications; and group 2 included those who had received ESIs $>10$ times, with a cumulative administered triamcinolone dose $>200 \mathrm{mg}$.

RESULTS: Patients in group 2 showed lower BMD in the femoral neck and total femur. However, no significant intergroup differences in the BMD of the lumbar spine were observed. The prevalences of osteoporosis and osteopenia in the lumbar spine and femoral neck were significantly higher in group 2; these patients also had lower femoral neck BMD Z-scores.

CONCLUSIONS: Multiple ESIs (approximately 14 injections with a cumulative triamcinolone dose of approximately $400 \mathrm{mg}$ ) can reduce BMD in postmenopausal women with low back pain.

Key Words: Bone mineral density; Corticosteroid; Epidural steroid injection; Low back pain; Postmenopausal women; Triamcinolone

$\mathrm{V}$ arious methods are used for managing low back pain (1), among which epidural steroid injection (ESI) is a commonly used technique $(2,3)$. ESIs are commonly used to manage chronic low back pain, using caudal, interlaminar and transforaminal approaches. Moreover, steroids are also used with other procedures, such as the intra-articular zygapophysial joints injection (2-4). However, corticosteroid therapy often results in bone loss and osteoporosis (5). Osteoporosis is a common problem, especially among postmenopausal women (6). Therefore, the use of ESIs in postmenopausal women is an important issue associated with bone loss. However, the ethics of pain management are intricately intertwined with and yet, in certain essential aspects, distinct from the traditional concepts and principles of patient care (6). The epidural injection of corticosteroids for the management of low back pain remains under debate and depends on the opinion of the practitioner.

There are many studies investigating bone mineral density (BMD) in patients taking oral corticosteroids (7-9). However, patients taking
La relation entre la densité minérale osseuse et de fréquentes injections épidurales de stéroïdes chez les femmes postménopausées ayant des douleurs lombaires

HISTORIQUE : L'injection épidurale de stéroïdes (IÉS) est l'un des principaux traitements non chirurgicaux des douleurs lombaires. La corticothérapie provoque souvent une perte osseuse et une ostéoporose. Dans des études antérieures, la densité minérale osseuse $(\mathrm{DMO})$ était évaluée après un relativement petit nombre d'injections épidurales et des doses totales relativement faibles de corticoïdes. Cependant, la relation entre la DMO et les multiples IÉS n'a pas encore été établie.

OBJECTIF : Explorer la relation entre la DMO et les multiples IÉS chez les femmes postménopausées ayant des douleurs lombaires.

MÉTHODOLOGIE : Les chercheurs ont examiné les dossiers médicaux de femmes postménopausées ayant des douleurs lombaires traitées avec ou sans IÉS. Ils ont mesuré la DMO dans la colonne lombaire, le col du fémur et l'ensemble du fémur après les traitements. Au total, 71 patientes ont été réparties en deux groupes. Le groupe 1 se composait de patientes qui avaient reçu des médicaments sans IÉS et le groupe 2, de patientes qui avaient reçu des IÉS plus de dix fois, pour une dose cumulative de plus de $200 \mathrm{~g}$ de triamcinolone.

RÉSULTATS : Les patientes du groupe 2 présentaient une DMO moins élevée dans le col du fémur et l'ensemble du fémur. Les différences de DMO de la colonne lombaire entre les groupes n'étaient toutefois pas significatives. La prévalence d'ostéoporose et d'ostéopénie de la colonne lombaire et du col du fémur était beaucoup plus élevée dans le groupe 2. Ces patientes présentaient également un écart réduit moins élevé de DMO dans le col du fémur.

CONCLUSIONS : De multiples IÉS (environ 14 injections, pour une dose cumulative d'environ $400 \mathrm{mg}$ de triamcinolone) peuvent réduire la DMO chez les femmes postménopausées ayant des douleurs lombaires.

the medicine orally generally receive high doses of the corticosteroids. Moreover, orally administered corticosteroids have different absorption characteristics and effects than those associated with epidural injections; therefore, a direct comparison between the two is difficult. In previous studies, BMD was evaluated after epidural injections of a relatively small number and relatively low total doses of corticosteroids $(10,11)$. However, the relationship between BMD and ESIs for the treatment of chronic low back pain has not been thoroughly investigated. In the present study, we aimed to explore the relationship between BMD and multiple ESIs in postmenopausal women with low back pain.

\section{METHODS}

The present study was a retrospective analysis of postmenopausal women with low back pain who were admitted to the pain management practice centre of the Kangwon National University Hospital (Gangwon-do, South Korea) between July 2009 and December 2012. The study was designed according to the Strengthening the Reporting

Department of Anesthesiology and Pain Medicine, Kangwon National University Hospital, School of Medicine, Kangwon National University, Chuncheon, Gangwon-do, South Korea

Correspondence: Dr Byeongmun Hwang, Department of Anesthesiology and Pain Medicine, Kangwon National University Hospital, School of Medicine, Kangwon National University, Chuncheon, Gangwon-do 200-701, South Korea. Telephone 82-33-258-2238,

fax 82-33-257-4636, e-mail arim14@kangwon.ac.kr 
TABLE 1

Characteristics of the patients treated with and without epidural steroid injections (ESIs)

\begin{tabular}{|c|c|c|c|}
\hline Characteristic & $\begin{array}{l}\text { Group 1* } \\
(n=40)\end{array}$ & $\begin{array}{c}\text { Group } 2^{\dagger} \\
(n=31)\end{array}$ & $\mathbf{P}$ \\
\hline Age, years & $70 \pm 6.8$ & $69 \pm 8.5$ & NS \\
\hline Weight, kg & $56 \pm 4.6$ & $58 \pm 5.7$ & NS \\
\hline Height, cm & $153 \pm 7.3$ & $151 \pm 9.1$ & NS \\
\hline \multicolumn{4}{|l|}{ Bone mineral density, $\mathrm{g} / \mathrm{cm}^{2}$} \\
\hline Lumbar spine & $0.923 \pm 0.154$ & $0.913 \pm 0.218$ & NS \\
\hline Total femur & $0.807 \pm 0.126$ & $0.751 \pm 0.081$ & $0.035^{\ddagger}$ \\
\hline Femoral neck & $0.743 \pm 0.114$ & $0.685 \pm 0.085$ & $0.023^{\ddagger}$ \\
\hline \multicolumn{4}{|l|}{ Z-score } \\
\hline Lumbar spine & $0.05 \pm 1.162$ & $-0.02 \pm 1.606$ & NS \\
\hline Total femur & $-0.15 \pm 0.905$ & $-0.49 \pm 0.907$ & NS \\
\hline Femoral neck & $0.29 \pm 0.857$ & $-0.49 \pm 0.860$ & $0.001^{\ddagger}$ \\
\hline Total number of ESIs & - & $14.7 \pm 3.1$ & \\
\hline $\begin{array}{l}\text { Duration between the first and } \\
\text { last ESI, months }\end{array}$ & & $34.4 \pm 2.6$ & \\
\hline $\begin{array}{l}\text { Cumulative triamcinolone } \\
\text { dose, } \mathrm{mg}\end{array}$ & - & $394 \pm 81$ & \\
\hline
\end{tabular}

Data presented as mean $\pm S D$ unless otherwise specified. "Group 1 patients received treatment without ES/s; ${ }^{\dagger}$ Group 2 patients received $>10$ ES/s, with a cumulative administered triamcinolone dose $>200 \mathrm{mg} ;{ }^{\ddagger} P<0.05$ compared with group 1. NS Not significant

of Observational Studies in Epidemiology (STROBE) guidelines (12), was approved by the local institutional review board and was conducted in accordance with the Declaration of Helsinki (13). The study has also been registered with the Clinical Research Information Service of South Korea (http://cris.nih.go.kr; no. KCT0000672). Interviews were conducted after reviewing the subjects' medical records.

A total of 3126 patients visited the pain centre for low back pain management between July 2009 and December 2012. Of the 3126 patients, 84 received radiofrequency therapy or median branch blocks. A total of 71 patients ( $\geq 50$ years of age) who satisfied the inclusion criteria were eventually selected and enrolled in the study. Group 1 consisted of 40 patients who had received non-ESI medications (ie, nonsteroidal anti-inflammatory drugs and muscle relaxants), and group 2 consisted of 31 patients who had received $>10$ ESIs, with a cumulative triamcinolone dose $>200 \mathrm{mg}$.

Patients with a postmenopausal status, a history of chronic low back pain lasting at least six months and who had undergone BMD assessments after treatment for low back pain were included in the study. The exclusion criteria were: a history of comorbidities known to affect bone metabolism such as cancer, pituitary disease, thyroid disease, rheumatic disease, renal failure or adrenal disease; a history of taking medications known to affect bone metabolism such as bisphosphonates, calcium or vitamin $\mathrm{D}$; osteoporotic fractures; and previous lumbar spine or femoral surgery.

Each patient's age at menopause, medical history and status with regard to smoking, drinking, physical activity and exercise were obtained using a questionnaire. Physical activity was categorized into three groups: low (absence of moderate or vigorous activity on a weekly basis); moderate (moderate activity at least once per week); and vigorous (vigorous activity at least once per week) (14).

The determinant used when considering the use of epidural injections was function-limiting, severe pain that was not responsive to noninvasive treatments over a two-week period. Group 2 patients received the initial two or three ESIs at two-week intervals. Additional epidural injections were provided based on the patient's response (such as a decrease in pain relief $<50 \%$ ) at two-month intervals. The total annual dose of steroid was limited to $3 \mathrm{mg} / \mathrm{kg}$ of triamcinolone,
TABLE 2

Lifestyle characteristics of the patients treated with and without epidural steroid injections

\begin{tabular}{lcc}
\hline Characteristic & Group $\mathbf{1}^{*}(\mathbf{n = 4 0 )}$ & Group $\mathbf{2}^{\dagger}(\mathbf{n = 3 1 )}$ \\
\hline Smoker & $2(5)$ & $1(3)$ \\
Alcohol drinker & $6(15)$ & $4(13)$ \\
Regularly exercise & $6(15)$ & $2(6)$ \\
Physical activity & & \\
Low & $8(20)$ & $10(32)$ \\
Moderate & $21(53)$ & $18(58)$ \\
Vigorous & $11(27)$ & $3(10)$ \\
\hline
\end{tabular}

Data presented as $n$ (\%). "Group 1 patients received treatment without epidural steroid injections; †'Group 2 patients received >10 epidural steroid injections, with a cumulative administered triamcinolone dose $>200 \mathrm{mg}$

according to the guidelines for the proper use of ESIs (15). The average period between the first and last ESI was 34.4 months. During this time period, the patients did not receive other interventions for low back pain.

The ESIs were administered at the lumbar spine level, with a mixture of $8 \mathrm{~mL}$ lidocaine hydrochloride $(0.5 \%$, preservative free) and triamcinolone. All participants received an epidural injection of $40 \mathrm{mg}$ of triamcinolone as their first injection. However, some participants reported side effects such as flushing, an itching sensation and hives. Therefore, participants received subsequent epidural injections of either $20 \mathrm{mg}$ or $40 \mathrm{mg}$ triamcinolone, depending on their tolerance. All of the procedures were performed by one physician, under fluoroscopic guidance, in a sterile, ambulatory surgical setting, with appropriate monitoring. Sedation with midazolam and fentanyl were administered, if necessary.

The BMD values of the lumbar spine (L2 to L4), femoral neck and total femur were measured by dual-energy $\mathrm{x}$-ray absorptiometry using Lunar Prodigy (GE Healthcare, USA) and were expressed as absolute values $\left(\mathrm{g} / \mathrm{cm}^{2}\right)$. Calibration procedures were performed daily using the appropriate phantoms provided by the manufacturer; the long-term precision of the daily scans was $0.994 \mathrm{~g} / \mathrm{cm}^{2}$ in BMD units. The interassay coefficient of variation for BMD was between 0.07 and 0.09 . $\mathrm{BMD}$ values were also expressed as $\mathrm{T}$-scores and $\mathrm{Z}$-scores. $\mathrm{T}$-scores were calculated in terms of the difference between the measured BMD and the mean BMD of healthy young adult Korean women (20 to 40 years of age) matched for ethnicity divided by the SD of the young adult population. Z-scores were calculated by the number of SDs above or below the means for age, weight $(25 \mathrm{~kg}$ to $100 \mathrm{~kg}$ ) and ethnicity with reference to the normative data provided by GE Healthcare. Osteoporosis was defined as a T-score $\leq-2.5$ and osteopenia was defined as a T-score $>-2.5$ but $<-1.0$, according to the WHO criteria. Lower-than-expected BMD was defined as a Z-score $\leq-2.0 \mathrm{SD}$ from the reference data (16).

\section{Statistical analysis}

The data are presented as mean $\pm \mathrm{SD}$. Unpaired $t$ tests were used to compare differences in age, weight, height and BMD between the groups. Fisher's exact test was used to compare differences in smoking, alcohol consumption and exercise. Physical activity levels were compared using the Mann-Whitney $U$ test. The prevalences of osteoporosis and osteopenia were also compared using the Mann-Whitney U test. In all comparisons, $\mathrm{P}<0.05$ was considered to be statistically significant. The statistical analyses were performed using SPSS version 19.0 (IBM Corporation, USA).

\section{RESULTS}

The subjects' characteristics are presented in Table 1. No significant differences in age, weight or height were observed between the groups. The groups had similar lumbar spinal BMDs. However, the BMDs of the femoral neck and total femur were significantly lower in group 2 
TABLE 3

Prevalences of osteoporosis and osteopenia among the patients treated with and without epidural steroid injections

\begin{tabular}{|c|c|c|c|c|c|c|c|}
\hline & \multicolumn{2}{|c|}{ Normal } & \multicolumn{2}{|c|}{ Osteopenia $^{\dagger}$} & \multicolumn{2}{|c|}{ Osteoporosis ${ }^{\ddagger}$} & \multirow[b]{2}{*}{$\mathbf{P}$} \\
\hline & Group1§ & Group 2T & Group 1 & Group 2 & Group 1 & Group 2 & \\
\hline Lumbar spine & $19 / 40(47)$ & 6/31 (19) & $13 / 40(33)$ & $14 / 31(45)$ & $8 / 40(20)$ & 11/31 (36) & $0.019^{* *}$ \\
\hline Total femur & $10 / 40(25)$ & 6/31 (19) & $23 / 40(58)$ & 20/31 (65) & $7 / 40(17)$ & $5 / 31(16)$ & NS \\
\hline
\end{tabular}

Data presented as $n / n$ (\%) unless otherwise specified. *Bone mineral density (BMD) data are based on T-scores; O Osteopenia was defined as -2.5 SD <BMD T-score $<-1.0$ SD; $¥$ Osteoporosis was defined as BMD T-score $\leq-2.5$ SD; §Group 1 patients $(n=40)$ received treatment without epidural steroid injections. "Group 2 patients $(n=31)$ received $>10$ epidural steroid injections, with a cumulative administered triamcinolone dose $>200 \mathrm{mg}$; ${ }^{* *} P<0.05$ compared with group 1 . NS Not significant

TABLE 4

Bone mineral density-related outcomes (Z-scores)* among the patients treated with and without epidural steroid injections

\begin{tabular}{|c|c|c|c|c|c|c|}
\hline & \multicolumn{2}{|c|}{$Z \geq 0$} & \multicolumn{2}{|c|}{$-2<Z<0$} & \multicolumn{2}{|c|}{$Z \leq-2$} \\
\hline & Group $1^{\dagger}$ & Group $2^{\ddagger}$ & Group 1 & Group 2 & Group 1 & Group 2 \\
\hline Lumbar spine & $21 / 40(53)$ & $14 / 31(45)$ & $17 / 40(42)$ & $13 / 31(42)$ & 2/40 (5) & $4 / 31$ (13) \\
\hline Total femur & $17 / 40(43)$ & $10 / 31(32)$ & $22 / 40(54)$ & 20/31 (65) & $1 / 40(3)$ & 1/31 (3) \\
\hline
\end{tabular}

Data presented as $n / n$ (\%) unless otherwise specified. *Z-score is the number of SDs above or below the mean for the patient's age, sex and ethnicity; ${ }^{\dagger}$ Group 1 patients $(n=40)$ received treatment without epidural steroid injections; $¥$ Group 2 patients $(n=31)$ received $>10$ epidural steroid injections, with a cumulative administered triamcinolone dose $>200 \mathrm{mg}$

than in group $1(\mathrm{P}<0.05)$. The BMD Z-scores of the femoral neck were also significantly lower in group $2(\mathrm{P}<0.001)$. The mean total number of ESIs was 14.7 , and the mean cumulative administered dose of triamcinolone was $394 \mathrm{mg}$.

Table 2 presents the lifestyle characteristics of the patients. There were no statistically significant differences between the two groups with respect to smoking, alcohol consumption, exercise or physical activity. The BMD-related outcomes of the treatments are listed in Table 3. The prevalences of osteoporosis and osteopenia in the lumbar spine and femoral neck were significantly lower in group $1(\mathrm{P}<0.05)$. The analyses were repeated after correcting for age (Table 4). Lowerthan-expected BMDs of the lumbar spinal, total femoral and femoral neck regions were present in $5 \%, 3 \%$ and $0 \%$ of the patients in group 1 and $13 \%, 3 \%$ and $6 \%$ of those in group 2 , respectively.

\section{DISCUSSION}

The present study showed that postmenopausal women who received multiple ESIs (approximately 14 injections with a cumulative triamcinolone dose of approximately $400 \mathrm{mg}$ ) had lower BMD in the femoral neck and total femur regions. This observation may be the result of the negative effect of frequent administration of epidural steroids on BMD in postmenopausal women with low back pain.

Corticosteroids are widely used as effective agents for controlling low back pain and sciatica, but osteoporosis is a common problem associated with their long-term use $(7,8)$. These drugs can affect bones through multiple pathways, influencing both bone formation and resorption $(7,8)$. Corticosteroid-induced bone loss is dose dependent, suggesting that even low doses can cause bone loss in some patients (7-9). The dose and duration of corticosteroid therapy are considered by many investigators to be the most important determinants of bone loss $(15,17,18)$.

Previous studies recommended that the use of a triamcinolone dosage $\geq 3 \mathrm{mg} / \mathrm{kg}$ for one year should be limited to prevent osteoporosis $(8,19,20)$. Moreover, patients with cumulative exposure to $\geq 200 \mathrm{mg}$ of triamcinolone are at greater risk, which increases further with increasing glucocorticoid exposure $(10,21)$. Some previous studies evaluating patients receiving low-dose steroid therapy showed no significant relationship between epidural steroid therapy and BMD in postmenopausal women with low back pain $(10,21)$. However, other studies have demonstrated that those receiving high-dose steroid therapy $(>1 \mathrm{~g})$ are at risk for lower $\operatorname{BMD}(22,23)$. However, in the present study, which evaluated patients receiving intermediate-dose steroid therapy, we observed that a cumulative triamcinolone dose of approximately $400 \mathrm{mg}$ may have a negative effect on BMD. This result, if confirmed by additional studies, will facilitate the development of guidelines for the proper use of epidural steroids in patients with low back pain.

Low-dose epidural steroid therapy may not have a significant effect on BMD, because ESIs with a cumulative triamcinolone dose of $200 \mathrm{mg}$ did not demonstrate a significant correlation with BMD in a previous study (10). However, patients who had received ESIs of $400 \mathrm{mg}$ of triamcinolone, as reported in the present study, showed lower BMDs of the total femur and femoral neck than those who did not receive this treatment. These results may be explained by the cumulative effect of epidural steroid administration. However, they may also be attributed to pre-existing low BMD, because patients who receive ESIs have lower physical activity and more severe disease that does not respond to medications $(24,25)$. Each of the ESI recipients in the present study had disease that was not controlled by medications, thus causing severe and prolonged pain. Therefore, they may have had low BMD scores before treatment, which may explain why the BMD in these patients was lower than that of patients not treated with ESIs. In the present study, the mean BMD values of the lumbar spine, total femur and femoral neck were $0.923 \mathrm{~g} / \mathrm{cm}^{2}, 0.807 \mathrm{~g} / \mathrm{cm}^{2}$ and $0.743 \mathrm{~g} / \mathrm{cm}^{2}$, respectively, in the patients treated without ESIs; and $0.913 \mathrm{~g} / \mathrm{cm}^{2}$, $0.751 \mathrm{~g} / \mathrm{cm}^{2}$ and $0.685 \mathrm{~g} / \mathrm{cm}^{2}$, respectively, in those treated with ESIs. These values are similar to previous findings in postmenopausal Korean women: $1.02 \mathrm{~g} / \mathrm{cm}^{2}$ to $0.89 \mathrm{~g} / \mathrm{cm}^{2}, 0.89 \mathrm{~g} / \mathrm{cm}^{2}$ to $0.69 \mathrm{~g} / \mathrm{cm}^{2}$ and $0.84 \mathrm{~g} / \mathrm{cm}^{2}$ to $0.71 \mathrm{~g} / \mathrm{cm}^{2}$ in the lumbar spine, total femur and femoral neck, respectively $(10,11,26-28)$.

The true incidence and prevalence of osteoporosis in patients receiving ESIs are unknown, and only limited data are available. Among patients receiving ESIs, the prevalence of osteoporosis is considered to be proportional to the corticosteroid dosage (21). In postmenopausal Korean women, the prevalences of osteoporosis are reportedly $49 \%$ to $51 \%$ in the lumbar spine, $22 \%$ in the total femur and $11 \%$ to $23 \%$ in the femoral neck $(11,28)$. In agreement with these data, the present study revealed that the prevalences of osteoporosis in patients treated with and without ESIs were 36\% and 20\% in the lumbar spine, $16 \%$ and $17 \%$ in the total femur, and $29 \%$ and $10 \%$ in the femoral neck, respectively. The prevalences of osteoporosis and osteopenia in the lumbar spine and femoral neck were significantly lower in patients who had not received ESIs. However, the prevalences of osteoporosis and osteopenia among patients in the present study were 
similar to those in postmenopausal Korean women reported in previous studies.

The BMD of the lumbar spine was not significantly different between the groups. Furthermore, the prevalence of osteoporosis was lower than that reported previously $(11,29)$. These results may be explained by increased osteophyte formation due to a pre-existing disease or increased physical activity caused by improvement in low back pain.

The BMD Z-score is considered to be the best measure to compare patients in a population with different age groups (16). In the present study, only a few patients with low BMD Z-scores (Z-score $\leq-2.0 \mathrm{SD}$ ) were treated with ESIs, and these patients showed no significant differences with the group treated with other medications. A slightly higher number of patients had low lumbar spine $\mathrm{Z}$-scores. This result may be attributed to the underlying disease causing low back pain. The data imply that multiple ESIs do not have severe pathological effects, even if they lower BMD.

The typical risk factors for osteoporosis, such as advanced age, female sex, cumulative steroid exposure and underlying disease, may have independent and additive effects on bone loss in corticosteroidtreated patients $(11,29,30)$. BMD is a major determinant of the fracture risk in patients with corticosteroid-induced osteoporosis $(29,30)$. Thus, all patients initiating long-term treatment with corticosteroids should obtain a baseline BMD measurement. The total annual dose of steroid should also be limited. Furthermore, pharmacological treatment with agents such as calcium, vitamin D, estrogen and bisphosphonate, as well as exercise, are required for patients with frequent corticosteroid exposure $(8,25,29)$. Although evidence to define the incidence of complications arising from ESIs is insufficient, adequate proof is available to support limiting the annual dose to prevent complications such as osteoporosis and vertebral fractures $(7,8)$. Agents other than steroids can also be used $(31,32)$; for example, clonidine has been safely used in epidural injections to treat low back pain and sciatica, and as an adjuvant to local anesthetics $(33,34)$. Because corticosteroid-induced bone loss is dose dependent and low-dose corticosteroid therapy is effective for low back pain and sciatica $(8,35)$, practitioners should use only the minimal effective dose of corticosteroids while considering the adverse effects of the drug.

Injectable corticosteroids commonly used for lumbar ESIs include dexamethasone, methylprednisolone, triamcinolone and betamethasone (2-4). Park et al (36) reported triamcinolone to be more effective than dexamethasone for short-term outcomes in patients with lumbar radiculopathy. When triamcinolone is mixed with a local anesthetic and saline solution, the advantages include potentially less precipitation, an evenly distributed drug, less sodium retention, prominent anti-inflammatory effects and relatively long working times, as well as fewer side effects, including vascular occlusion (37-39). For these reasons, we typically use formulations of triamcinolone.

The present study had several limitations. First, it had a retrospective design. However, a prospective study is difficult to perform because the frequent use of high-dose corticosteroids is unethical in these circumstances. Second, the present study does not indicate the allowable annual dose of corticosteroids when considering the effects of their long-term accumulation in patients receiving ESIs. Randomized controlled trials are needed to identify patients who are most likely to benefit from this treatment, and to determine the frequency and duration of administration while also considering the adverse effects. Despite these limitations, to the best of our knowledge, this is the first study examining the relationship between BMD and frequent ESIs in postmenopausal women with low back pain.

\section{CONCLUSION}

The postmenopausal women who had received multiple ESIs (approximately 14 injections with a cumulative triamcinolone dose of approximately $400 \mathrm{mg}$ ) showed lower BMD in the femoral neck and total femur. Although baseline BMD values are unknown in the two groups, these results suggest an association between the frequent administration of triamcinolone ESIs and low BMD values in postmenopausal women with low back pain.

ACKNOWLEDGEMENT: This study was supported by 2013 Research Grant from Kangwon National University.

DISCLOSURES: The authors have no conflicts of interest to declare.

\section{REFERENCES}

1. Scott NA, Moga C, Harstall C. Managing low back pain in the primary care setting: The know-do gap. Pain Res Manag 2010:15:392-400

2. Benyamin RM, Manchikanti L, Parr AT, et al. The effectiveness of lumbar interlaminar epidural injections in managing chronic low back and lower extremity pain. Pain Physician 2012;15:E363-404.

3. Mailis A, Taenzer P. Evidence-based guideline for neuropathic pain interventional treatments: Spinal cord stimulation, intravenous infusions, epidural injections and nerve blocks. Pain Res Manag 2012:17:150-8.

4. Manchikanti L, Falco FJ, Singh V, et al. Utilization of interventional techniques in managing chronic pain in the Medicare population: Analysis of growth patterns from 2000 to 2011. Pain Physician 2012;15:E969-82

5. Chiluka VL, Banji D, Banji OJF, Sollu M, Pandra SB. Glucocorticoid induced osteoporosis. Intern J Pharm Sci Rev Res 2010;53:124-31.

6. Fishman SM, Ballantyne JC, Rathmell JP. Bonica's Management of Pain, 4th edn. Philadelphia: Lippincott Williams \& Wilkins, 2009:145-51.

7. Mitra R. Adverse effects of corticosteroids on bone metabolism: A review. PM R 2011;3:466-71.

8. Bouvard B, Legrand E, Audran M, Chappard D. Glucocorticoidinduced osteoporosis: A review. Clin Rev Bone Miner Metab 2010;8:15-26

9. van Staa TP, Leufkens HG, Abenhaim L, Zhang B, Cooper C. Oral corticosteroids and fracture risk: Relationship to daily and cumulative doses. Rheumatology 2000;39:1383-9.

10. Kang SS, Hwang B, Son H, Cheong IY, Lee SJ, Chung TY. Changes in bone mineral density in postmenopausal women treated with epidural steroid injections for lower back pain. Pain Physician 2012;15:229-36.

11. Yi Y, Hwang B, Son H, Cheong IY. Low bone mineral density, but not epidural steroid injection, is associated with fracture in postmenopausal women with low back pain. Pain Physician 2012;15:441-9.

12. Vandenbroucke JP, Von Elm E, Altman DG, et al. Iniciativa STROBE. Strengthening the reporting of observational studies in epidemiology (STROBE): Explanation and elaboration. Gac Sanit 2009;23:158.

13. Krleža-Jerić K, Lemmens T. 7th Revision of the Declaration of Helsinki: Good news for the transparency of clinical trials. Croat Med J 2009;50:105-10.

14. Hamer M, Stamatakis. Screen-based sedentary behavior, physical activity, and muscle strength in the English Longitudinal Study of Ageing. PLoS One 2013;8:E66222.

15. Deer T, Ranson M, Kapural L, Diwan SA. Guidelines for the proper use of epidural steroid injections for the chronic pain patient. Tech Reg Anesth Pain Manage 2009;13:288-95.

16. Schtscherbyna A, Pinheiro M , Mendonca L, et al. Factors associated with low bone mineral density in a Brazilian cohort of vertically HIV-infected adolescents. Int J Infect Dis 2012;16:872-8.

17. Baxter JD. Advances in glucocorticoid therapy. Adv Intern Med 2000;45:317-49.

18. Cohen S, Levy RM, Keller M, et al. Risedronate therapy prevents corticosteroid-induced bone loss. Arthritis Rheum 1999;42:309-18.

19. Laan RF, van Riel PL, van de Putte LB, van Erning LJ, van't Hof MA, Lemmens JA. Low-dose prednisone induces rapid reversible axial bone loss in patients with rheumatoid arthritis. Ann Intern Med 1993;119:963-8.

20. Gaber TA-ZK, McGlashan KA, Love S, Jenner JR, Crisp AJ. Bone density in chronic low back pain. Clin Rehabil 2002;16:867-70.

21. Dubois EF, Wagemans MF, Verdouw BC, et al. Lack of relationships between cumulative methylprednisolone dose and bone mineral density in healthy men and postmenopausal women with chronic low back pain. Clin Rheumatol 2003;22:12-7. 
22. van Staa TP, Leufkens HG, Cooper C. The epidemiology of corticosteroid-induced osteoporosis: A meta-analysis. Osteoporos Int 2002;13:777-87.

23. de Vries F, Bracke M, Leufkens HG, Lammers J-W, Cooper C, van Staa TP. Fracture risk with intermittent high-dose oral glucocorticoid therapy. Arthritis Rheum 2007;56:208-14.

24. Cui LH, Choi JS, Shin MH, et al. Prevalence of osteoporosis and reference data for lumbar spine and hip bone mineral density in a Korean population. J Bone Miner Metab 2008;26:609-17.

25. Smith EM, Comiskey CM, Carroll AM. A study of bone mineral density in adults with disability. Arch Phys Med Rehabil 2009;90:1127-35.

26. Karakiriou SK, Douda HT, Tokmakidis SP. The role of exercise in the prevention and treatment of osteoporosis in postmenopausal women. Arch Hellenic Med 2011;28:479-90.

27. Jeong IK, Cho SW, Kim SW, et al. Lipid profiles and bone mineral density in pre- and postmenopausal women in Korea. Calcif Tissue Int 2010;87:507-12.

28. Park JJ, Shin J, Youn Y, et al. Bone mineral density, body mass index, postmenopausal period and outcomes of low back pain treatment in Korean postmenopausal women. Eur Spine J 2010;19:1942-7.

29. Orimo H, Nakamura T, Hosoi Iki M, et al. Japanese 2011 guidelines for prevention and treatment of osteoporosis - executive summary. Arch Osteoporos 2012;7:3-20.

30. Ross PD. Osteoporosis: Frequency, consequences, and risk factors. Arch Intern Med 1996;156:1399-411.

31. Lee PB, Kim YC, Lee CJ, et al. The neurological safety of epidural pamidronate in rats. Korean J Pain 2010;23:116-23.
32. Lee JR, Lee PB, Choe G, et al. Evaluation of the neurological safety of epidurally-administered pregabalin in rats. Korean J Anesthesiol 2012;62:57-65.

33. Manickam A, Vakamudi M, Parameswari A, Chetan C. Efficacy of clonidine as an adjuvant to ropivacaine for caudal analgesia in children undergoing subumbilical surgery. J Anaesth Clin Pharma 2012;28:185-9.

34. Burgher AH, Hoelzer BC, Schroeder DR, Wilson GA, Huntoon MA. Transforaminal epidural clonidine versus corticosteroid for acute lumbosacral radiculopathy due to intervertebral disc herniation. Spine 2011;36: E293-300.

35. Kang SS, Hwang B, Son H, et al. The dosages of corticosteroid in transforaminal epidural steroid injections for lumbar radicular pain due to a herniated disc. Pain Physician 2011;14:361-70.

36. Park CH, Lee SH, Kim BI. Comparison of the effectiveness of lumbar transforaminal epidural injection with particulate and nonparticulate corticosteroids in lumbar radiating pain. Pain Med 2010;11:1654-8.

37. TisoRL, Cutler T, Catania JA, Whalen K. Adverse central nervous system sequelae sfter selective transforaminal block: The role of corticosteroids. Spine J 2004:4:468-74.

38. Benzon HT, Chew TL, McCarthy RJ, Benzon HA, Walega DR. Comparison of the particle sizes of different steroids and the effect of dilution: A review of the relative neurotoxicities of the steroids. Anesthesiology 2007;106:331-8.

39. Derby R, Lee S, Date E, Lee J, Lee C. Size and aggregation of corticosteroids used for epidural injections. Pain Med 2008;9:227-34. 


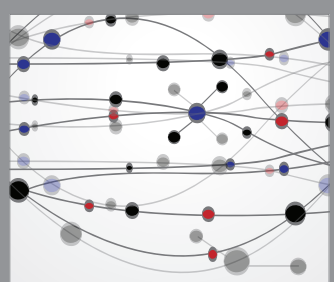

The Scientific World Journal
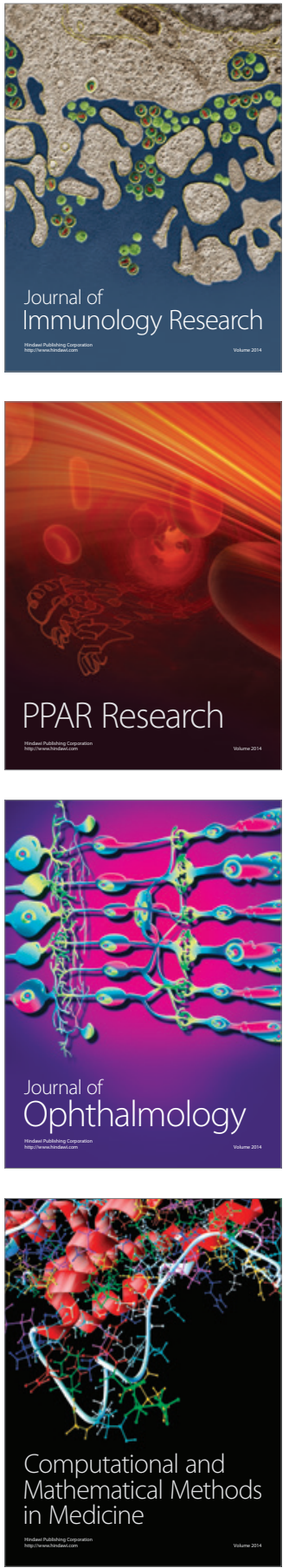

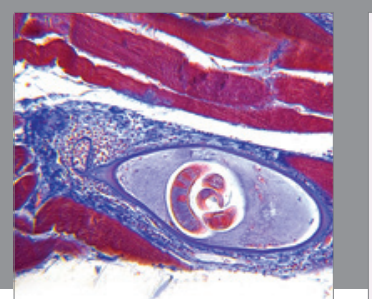

Gastroenterology Research and Practice

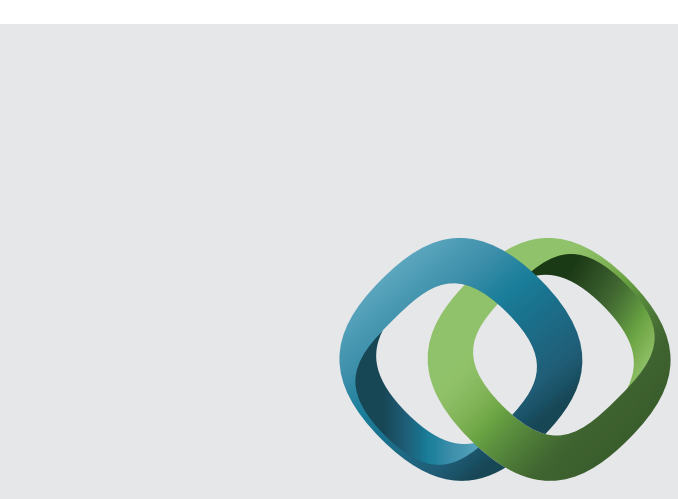

\section{Hindawi}

Submit your manuscripts at

http://www.hindawi.com
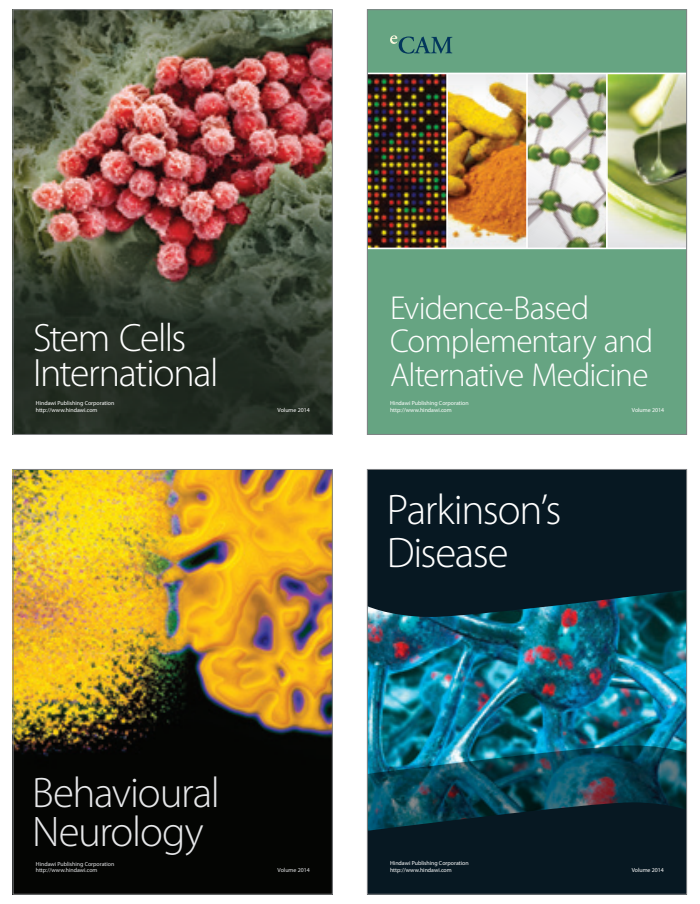
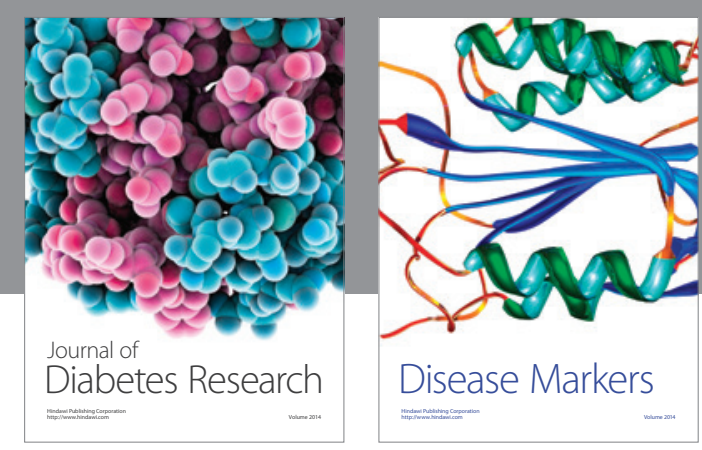

Disease Markers
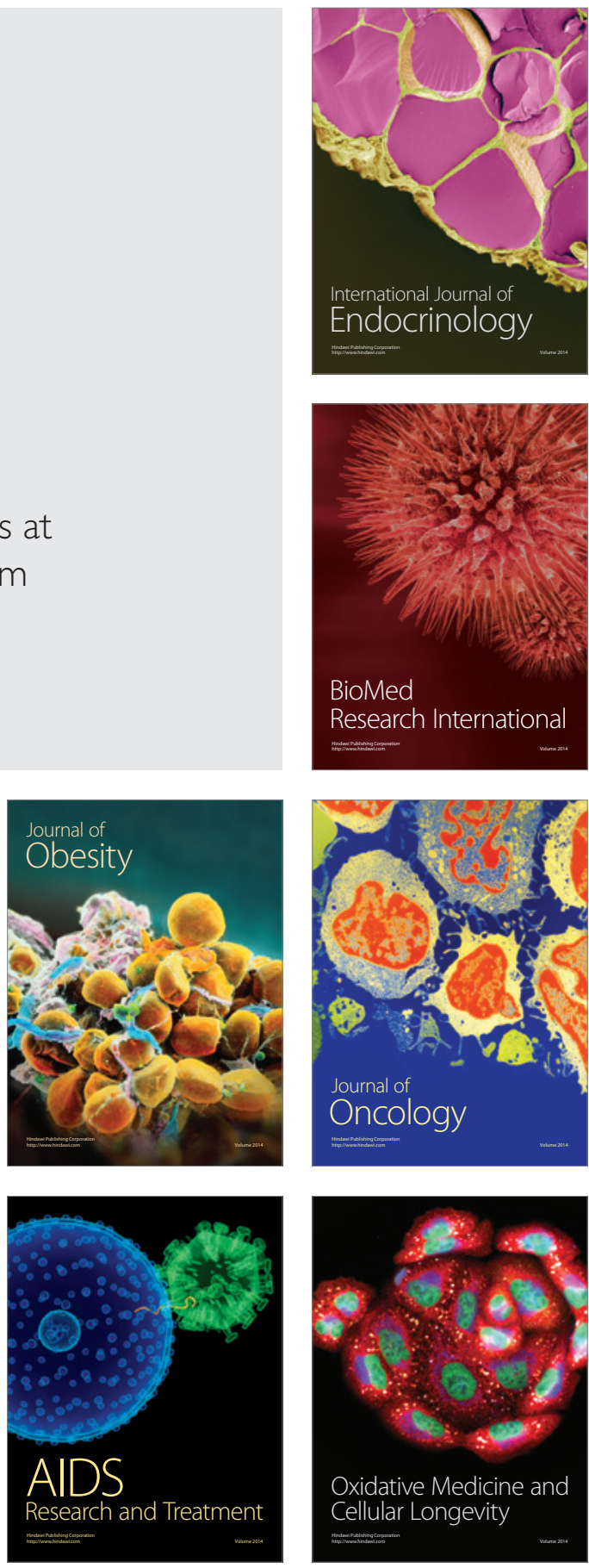